\title{
Social Workers' Narratives of Integrating Mindfulness into Practice
}

\section{Robyn Lynn \& Jo Mensinga}

To cite this article: Robyn Lynn \& Jo Mensinga (2015) Social Workers' Narratives of Integrating Mindfulness into Practice, Journal of Social Work Practice, 29:3, 255-270, DOI: 10.1080/02650533.2015.1035237

To link to this article: http://dx.doi.org/10.1080/02650533.2015.1035237

进 Published online: 27 Apr 2015.

Submit your article to this journal $\square$

Џ Article views: 366

Q View related articles $\square$

View Crossmark data $\longleftarrow$ 


\title{
Robyn Lynn and Jo Mensinga
}

\section{SOCIAL WORKERS' NARRATIVES OF INTEGRATING MINDFULNESS INTO PRACTICE}

\begin{abstract}
Mindfulness is increasingly important as a professional intervention in social work; however, little is known about how practitioners integrate a practice of eastern origins into a western context. To explore the integration of mindfulness in social work, we collected written stories from social workers who participated in two workshops in regional Australia. The participants developed their own individual written narratives about their understanding of and experience in using mindfulness, and contributed these to a larger group discussion. We identified four scenarios/plotlines within the collected stories and 'restoried' four examples of the participants' written narratives. The stories reveal that participants experience little dissonance when integrating mindfulness into their personal lives, but the process of incorporating it into their practice requires a complex negotiation between the participant's story of themselves as a practitioner of mindfulness, their 'professional story', stories of themselves as social workers and the story of social work in their professional knowledge landscape.
\end{abstract}

Keywords mindfulness; social work practice; meditation; epistemology; narrative

\section{Introduction}

Mindfulness is increasingly being researched and adopted in psychology, medicine and education, and has recently become more prominent in the social work literature. It is commonly defined as 'moment-to-moment awareness' or 'paying attention to the moment without judgement' and encourages attention to every movement, breath, feeling and thought - a 'consciousness alive to the present reality' (Hanh, 1976, p. 11).

In social work, the primary means of cultivating mindfulness is through formal and informal meditation practices and mindfulness-based applications. Although often associated with spiritual traditions, mindfulness can be learnt in a secular context without the support of a religion, as a means of facilitating awareness of the present 
moment (Hick, 2009, p. 2). This present moment orientation has been shown to be of benefit at the individual, group and community levels in social work, particularly in the development of increased attention, heightened self- awareness, cultivation of empathy and compassion, inner calm and peace, more insight and transformative ways of living and being (Coholic, 2005; Berceli \& Napoli, 2006; Minor \& Carlson, 2006; Hick, 2009).

As academics, we have included aspects of mindfulness and embodied awareness into our teaching in the university sector (Mensinga, 2010, 2011). However, following student questions and challenges about the value base underpinning these techniques, we developed an interest in exploring what, if any, ethical issues and/or dilemmas could arise when introducing mindfulness into social work practice settings. In another paper, we investigated the question 'is mindfulness value free?' and the implications (if any) for practitioners in the sector (Lynn, Mensinga, Tinning, \& Lundman, 2015). During this inquiry, we found that issues and tensions that arose were largely due to a perceived conflict of interest between the orientation and approach to practice, advocated by the social work profession and the workers' own experiences, training and understanding of mindfulness (Lynn et al., 2015). We concluded that while mindfulness has been shown to be a natural process that can be cultivated, its translation and evolution as an eastern practice into a western context requires the worker to merge different cultural and world views while also integrating their own personal experience into what they perceive as the espoused orientation and approach of the social work profession.

Healy contends that social workers' 'knowledge, purpose and skills bases - are substantially constructed in, and through, the environments in which [they] work' (2005, p. 4). Although this professional knowledge context is a 'dominant story' that is itself a part and parcel of the larger discourse that determines 'what is a profession', we began to wonder if the eastern origins of mindfulness actually mattered to social workers' as they came to know about and chose to use mindfulness in practice. Drawing on Fenstermacher's work (1994), whose interest was in the epistemological drivers underpinning knowledge creation in education, we identified four questions, we thought would help us address our concerns and help us better understand the process by which social workers integrated mindfulness into their practice:

- How do social workers come to know about mindfulness?

- What do social workers know about the effective use of mindfulness in social work?

- What knowledge do social workers consider essential for using mindfulness?

- Who do social workers trust to produce knowledge about mindfulness in social work?

With these questions in mind, we designed and delivered two workshops in two different regional cities along the East coast of Australia. The workshops provided a space for two separate groups of social workers to develop their own individual written narratives about mindfulness and to reflect on them in a larger group discussion. Following the workshop, we engaged in a process of focused reading of the written stories and reviewed notes and transcripts of the discussions. We familiarised ourselves with all the data by initially noting our own influence on the production of the 
narratives before identifying existing themes. This was followed by a further analysis of the collected stories, in which we used Clandinin and Connelly's (2000) threedimensional space approach to better understand the influences on the participating social workers' knowledge of and uptake of mindfulness in their practice.

In line with Clandinin and Connelly's (2000) narrative inquiry approach, we chose to restory and present four examples of the participants' written narratives to illustrate the dimensions/influence of place, time and social interaction made explicit during the workshops. In doing so, we revealed that the contextual nature of the profession as described by Healy (2005) and what we named the 'professional story' does indeed impact the process by which social workers story the acquisition of and use of mindfulness in practice. Similarly, in the process of exploring the four questions we raised in relationship with Fenstermacher's (1994) epistemological drivers, we conclude that the integration of mindfulness into social work practice is both a contextual and relational process that draws on the practitioner's personal experience/ knowledge of mindfulness (rather than on its religious underpinnings or theoretical understandings) and is influenced by their assessment of clients' needs within the agency context.

\section{Mindfulness in social work}

Interest in mindfulness in social work is a relatively recent phenomenon that is not fully integrated into the purpose, professional knowledge base and framework for practice. From the mid 2000s onwards, there have been a number of articles that indicate social work is engaging with mindfulness in individual, group and community interventions (Hick, 2009). They often use research undertaken in psychology, sociology or medicine to define and inform their knowledge of mindfulness and to provide the primary source of evidence of the effectiveness of mindfulness-based applications. These practices are used as a form of intervention, for cultivating a positive relationship with clients and as a mode of self-care for social workers and their clients (Hick \& Furlotte, 2009).

Mindfulness-based applications have their roots in the Buddhist traditions that describe it as a process or spiritual practice that involves distinct phases of development (Bodhi, 2011; Milton, 2011). In western psychology, there are a range of definitions and ways of operationalising mindfulness. The emphasis in these definitions has been on what it is and how to measure and develop it (Grossman \& Van Dam, 2011; Milton, 2011 , p. 24). These more recent accounts that have evolved through the science of mindfulness differ considerably from the traditional way it was defined. The recognition of these differences has led to an increase in discussion about whether the separation of mindfulness from its holistic roots in this work is useful and/or appropriate (Grossman \& Van Dam, 2011; Wallace, 2006, 2011).

Hick and Furlotte (2009) in their review of the definitions of mindfulness in social work identify Bishop et al.'s (2004) definition as the most commonly applied in social work. This definition has a health and wellness focus. Bishop et al. describe mindfulness as a two component model consisting of (a) 'self-regulation of attention so that it is maintained on immediate experience, thereby allowing for increased recognition of mental events in the present moment', and (b) 'adopting a particular orientation 
toward one's experiences in the present moment... characterized by curiosity, openness, and acceptance' (2004, p. 232). Drawing on this or similar definitions and knowledge from other sciences, the social work literature is beginning to develop its own theoretical, factual and practical knowledge (Trevithick, 2008) about the role and effectiveness of mindfulness for the social worker and the people with whom they work (Birnbaum \& Birnbaum, 2008; Hick, 2008, 2009; Hick \& Furlotte, 2009; Lee et al., 2009, Turner, 2009; Gause and Coholic, 2010; Segal et al., 2010) While it is important to generate this knowledge in the context of social work, we propose that this is only part of the story about social workers' knowledge and use of mindfulness and that an exploration of how they come to know about and integrate mindfulness practices is also necessary.

\section{The 'professional story' of social work}

Like other professions, social work lays claim to a particular way of knowing reality that forms part of a 'sacred story' on a professional knowledge landscape (Clandinin \& Connolly, 1996). In the case of social work, this story attempts to gloss over its religious-linked beginnings and adopt a materialist-positivist world view that both fosters a preferred humanist-modernist professional paradigm and helps to lay claim to knowledge and skills considered unique to social work (Payne, 1996; Fook et al., 2000; Fook, 2002; Lynn, 2010). However, what constitutes social work knowledge still remains inconclusive. While some authors choose to emphasise scientific, rational and legitimate knowledge, others focus on action and experience (Trevithick, 2008). Healy (2005), on the other hand, draws attention to a constructed knowledge space where the knowledge social workers assume to inform their purpose and practice is constantly negotiated between the different components that make up this space.

For our purposes then, we adopted Healy's (2005) model as a preferred way of understanding social work knowledge. We believed that Healy's (2005) concept of a constructed knowledge space better captured the challenges that practitioners would encounter when trying to integrate mindfulness into practice. The model itself identifies the practitioner's need to consider the institutional context (including public policies, laws, organisational policies as well as accepted practices); the formal professional base (service discourses from the human sciences, formal theories of practice, Judeo-Christian beliefs and formally accepted skills) and the worker's own individual framework (practice wisdom, developed theories of professional practice and skills and acquired knowledge) when actioning a particular practice approach. In our reckoning, then when choosing to adopt mindfulness, the social worker would not only need to reconcile their own experience of mindfulness within a western cultural context, but they would also need to navigate the dominant discourses that are strongly related to the materialist/positivist, humanist and modernist principles of objectivity, rationality and individualism which influence what is considered to be the appropriate knowledge for practice and practice decisions (Healy, 2005; Bell, 2012).

Clandinin and Connelly (1995) describe a similar process as that outlined by Healy (2005) when exploring how teachers made sense of presenting demands to negotiate their purpose and practice of teaching. However, in their work they propose that this process is best understood narratively and by way of metaphor. They suggest the image 
of a 'professional knowledge landscape' to depict the space in which teachers tell stories to account for their professional practice and understand the stories told in that space as the means by which teachers traverse the landscape. Drawing on both Clandinin and Connelly (1995) and Healy's (2005) work as ways to understand the integration of mindfulness into social workers' practice, we decided that collecting and exploring the stories social workers told about how they came to learn about and implemented mindfulness in their practice would provide answers to our questions as outlined in the beginning of this paper.

\section{Preparing for and hosting 'A conversation about mindfulness in social work'}

Our project was conducted at a regional university in Australia as part of its field education professional development program. The project was designed with the dual purpose of providing a professional development opportunity for social workers interested in participating in 'A conversation about mindfulness in social work', while at the same time producing material for our research on the inclusion of mindfulness approaches into social work practice.

The Social Work Field Education Unit invited social workers on their database to two professional development workshops. Each workshop was aimed at social workers who were familiar with mindfulness and who had either adopted it or were interested in its application in practice. On receiving Ethics Approval, interested participants were sent an information sheet which invited them to take part in our research on mindfulness in social work as part of their attendance. This information also outlined the aims of the research, data collection and management processes, the voluntary nature of participation, confidentiality and how the findings would be disseminated.

The workshops, of three hours duration, were held in two regional centres in Australia. The stated aims for the workshops were (a) to facilitate and collect participants' individual written narratives about their use (or desired use) of mindfulness in social work; (b) to provide a safe space in which participants could critically reflect upon and discuss their narrative and its meaning for their practice; (c) to develop a shared understanding of the possible tensions and dilemmas that may arise when using mindfulness, particularly in light of the ethics and values espoused by the profession, and (d) to identify any emerging implications for practice.

Each workshop began with some yoga and meditation practice. Information about the research aspect of the workshop was then revisited and formal consent sought to record and use participants' written narratives and conversations from the workshop. All of the participants provided consent. Nine participants engaged in one workshop and eight in the other. Seven participants in each of the workshops had adopted mindfulness into their work and wanted to further develop their use of it in their practice. Only three of the total participants had not had the opportunity to use meditation. Participants were from a range of government and non-government organisations.

At the beginning of each workshop, we identified ourselves as 'curious participants' rather than 'knowledge holders'. Although we hoped to elicit and engage with all the 'knowledge and experience' related to mindfulness in the room, being 
academics, we were aware of the possibility of inhibiting the conversation. Jo is a practitioner and teacher of yoga who at the time was the Field Education Coordinator and so knew some of the participants in the context of field placement organisation and support. Robyn practices Buddhist meditation. Though she had no specific role in field education, Robyn knew some of the participants in one of the workshops as fellow social workers. We were also aware that the stories were being written and collected as a professional development activity and this could potentially impact how the participants responded to the task of writing their practice stories.

Once introductions were completed, participants were given 15 minutes to write a story about their experience of mindfulness in practice. No definition of mindfulness was provided by us as we were interested in the participants' own understandings and believed these would emerge in the stories they told about the way they integrated mindfulness into their practice. However the 'Tree of Contemplative Practice' (see Figure 1) from the Centre for Contemplative Mind in Society was introduced to the participants before writing their stories to stimulate their thinking about and reflection on their own lived story of mindfulness practices. The tree provided participants with a

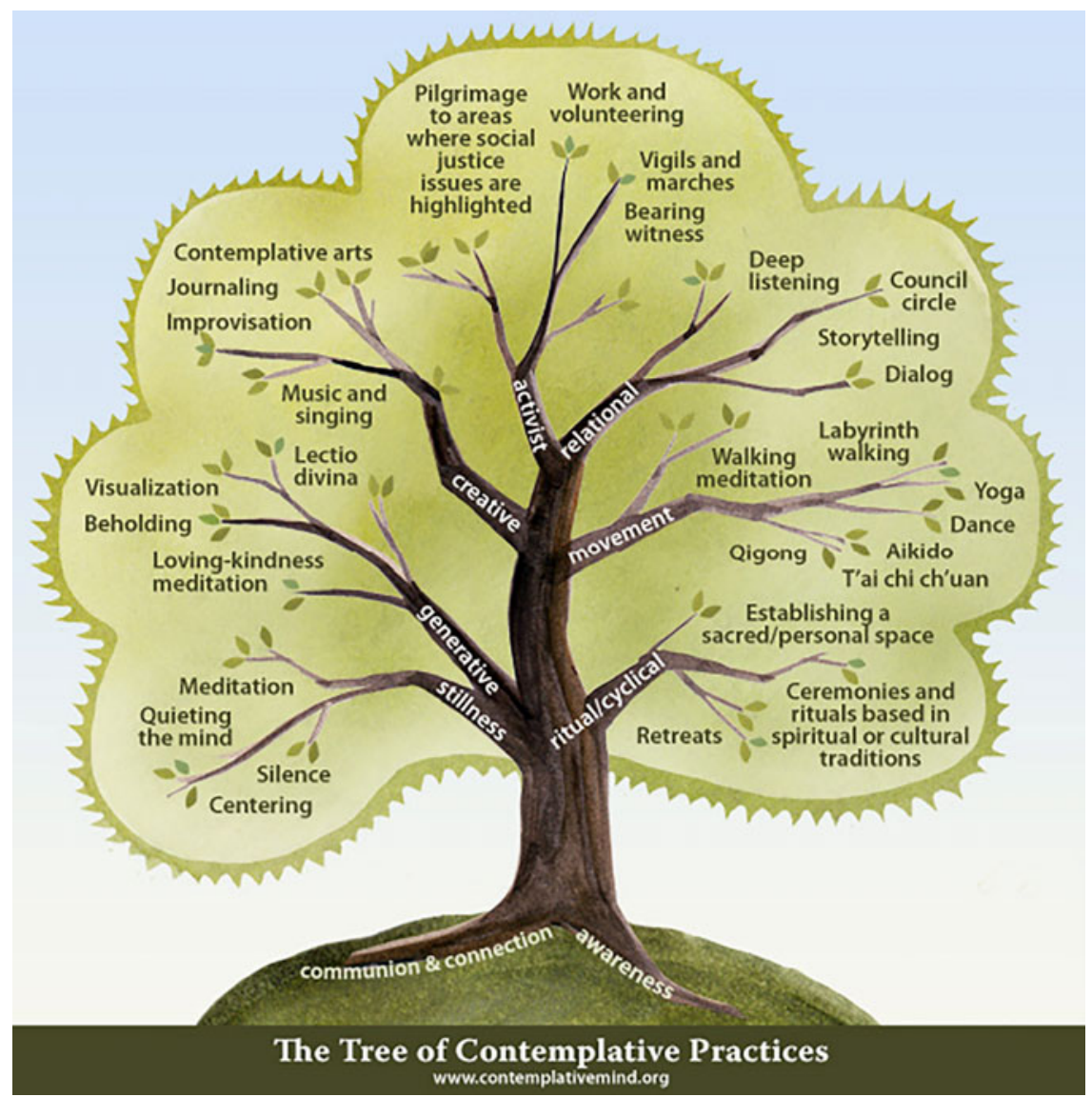

FIGURE 1 Tree of Contemplative Practices (http://www.contemplativemind.org/practices/tree. html) 
visual image of various contemplative practices. The roots of the tree symbolise the intention of the practices (communion, connection and awareness), while the branches represent different approaches that can be adopted to facilitate contemplation such as stillness, creativity or movement. This contributed to a broader understanding of mindfulness that could have had an effect on their individual definitions of mindfulness. We also provided four questions to stimulate their thinking: (1) what is your understanding of mindfulness? (2) how did you arrive at that understanding? (3) how did you use it in your practice? and (4) what tensions or ethical dilemmas do you encounter in integrating it into your practice?

\section{Exploring the collected stories of mindfulness}

Following the workshops, on two separate occasions, we each individually read all of the written narratives and then came together to share our understandings. On the first reading, we focused on the nature of the stories, exploring how our own position as workshop facilitators and as practitioner academics may have impacted the narratives (Riessmann, 2007). We also sought to identify any possible influence that the context and the workshop agenda may have had on the type of stories the practitioners wrote. During the second reading, we individually identified common themes and then came together to combine and mind map our responses. This led to a third analysis phase where we returned to Clandinin and Connelly's (1995) metaphor of a professional knowledge landscape and drew on Ollerenshaw and Creswell's (2002) summary of the key aspects of Clandinin and Connelly's (2000) three-dimensional space approach to analyse the practitioner narratives in more detail.

On our first reading, we were both struck by how the questions we had provided had influenced the way the participants had written their stories, and concluded that we too had been influenced by the 'professional story' when constructing the workshop. For example, the questions we provided for stimulation reflected the significance of the contextual nature of social work. We also noticed that when the participants wrote their stories, many tended to address the questions rather than use them as a source of stimulation for their thinking about their own larger story. In fact, rather than provide a 'whole' story, the written narratives consisted of fragmented descriptions of events, happenings and experiences - much like case notes or responses to short answer questions in an exam. Nevertheless, what at first seemed to be disjointed pieces of writing with no beginning, middle or end, on a closer reading emerged as 'big and small stories' (Bamberg, 2006) of mindfulness in social work. The effect of the Tree of Contemplative Practice, if any, on the quality of their stories was not clear. Following our second reading, we identified four main scenarios or plotlines emerging from the stories: mindfulness as a practice; mindfulness as a social construct; mindfulness as a negotiated practice and ethical issues associated with introducing mindfulness.

To better understand how these 'plotlines' assisted the participants to integrate mindfulness into their practice, we again revisited the stories and noticed that the linking of knowledge, context and identity within a particular space, place and time was important in both the practitioner's personal and/or professional experience. The emerging relationship between space, place and time prompted a final analysis where 
(Robyn) followed Ollerenshaw and Creswell's (2002) summary of Clandinin and Connelly's (2000) three-dimensional space approach to analyse the practitioner narratives. This approach enabled us to focus on the broader wholistic experience of the participants that was central in their stories and involved analysing the following elements in the individual participant stories: (i) personal and social interaction with others; (ii) continuity of past, present and future experiences and (iii) any specific situations or places in their experience (Clandinin \& Connelly, 2000). The initial threedimensional space narrative structure was then shared with (Jo) who reviewed the analysis. Through this process, we formed a new story that highlights the experiences and interactions that occurred in their narratives of mindfulness.

However, a limitation of this approach is that it continues in the tradition of using western empirical scientific methods to explore the use of mindfulness in social work. These methods retain the mind/body split that exist within the modernist 'professional story' of social work (Mensinga, 2011) and hinder any significant ontological and epistemological shift occurring in social work. It is only with more emphasis given to the empiricism of the visceral (Mensinga, 2011) and the contemplative or consciousness disciplines (Wallace, 2012) that the subjectively experienced mental states and processes that occur in the use of mindfulness in social work can become part of research observations and contribute to a real paradigm shift in social work.

\section{Narrative plotlines emerging from the stories of mindfulness in social work}

Consistent with Clandinin and Connelly's (2000) approach, we present our findings as a number of stories to illustrate the scenarios/plotlines we identified as the means that social workers use to navigate within the 'professional story' on the professional landscape. Moreover, like all the stories told and written in the workshop, these examples also provide insights into how social workers' knowledge of mindfulness involves the linking of knowledge, context and identity within a particular space, place and time in the practitioner's personal and professional life. While the stories presented here are based on fact, they are also 'fictionalised'. That is, the names and order of events within each of the identified plotlines have been reconstructed from the fragmented stories we collected. This process provides narrative coherence while maintaining confidentiality for the participants.

\section{Mindfulness is both a practice and a social construct}

Mari's story

I came to understand mindfulness through my own personal experience of trauma and awareness. I began by walking. I remember the pleasure of walking around on soft grass with no shoes for ten minutes a day and how it was an escape from the pain and struggle of postnatal depression. It helped me to stop listening to my depressed thoughts and voices and instead I began to listen to my breath, my body, to feel the sun on my skin and become more aware of colours, touch, and smells. 
I don't use walking as a practice anymore. Instead I enjoy visualisations and experience mindfulness as a way of being 'conscious'. But it was because of my initial experience and how it helped me that I still use mindfulness today and have shared various practices with my own children and with clients in the workplace. Professionally I draw on my personal experience when working with traumatised clients - especially with those who have underlying anxiety and PTSD. However, with them, I prefer to use art as a tool rather than other practices as I don't think the clients would feel safe if I asked them to close their eyes. When using art I aim to develop awareness and often give feedback on what I see and hear in my interactions with the client. For example, I might draw their attention to a grimace they have just made. Hmmm, as an aside though, I have noticed that clients who are what I call 'indoctrinated Christians' are wary of mindfulness.

\section{Morgans's story}

I became interested in mindfulness practices during the 1970s. I used to join a group of actors and dancers who would do yoga for the first hour of their daily class at University. Yoga became part of my personal life - I even took up fasting on a weekly basis for 3 years. However, it was when I lived in India and Papua New Guinea and became immersed in many of their cultural practices that I found that my own practice deepened. In India I would join the host where I lived when she did yoga and meditation - something she did for three hours each day. During this time I learnt to focus more on breathing and how to build a relationship with it and then integrate it with how I ate. I also used my focus on the breath as a way of living and relating to others. In Papua New Guinea the chanting and singing that women engaged in to ward off spirits and strengthen the community provided another experience of mindfulness for me. For me then, mindfulness has become a practice of focused awareness that is nurturing and is experienced through centring and inner stillness, reflection, and meditation (which can include breathing/yoga).

In my experience mindfulness is a cultural practice that can be adapted within our own. Although I am very aware of the 'new age' links that some people/ clients can attach to mindfulness and that the practices themselves originate from Hindu/Buddhist religions, I believe that the techniques can be utilized within the professional context of social work. I liken it to the fact that personally and as a culture I am [we are] quite happy to eat pasta, which is an Italian food from a mainly Catholic country, and curry from India. And I don't see this as being any different. In my professional practice then, if in my assessment I think the client and situation could benefit from the introduction of centring, reflection and/or meditation I will incorporate breathing, meditation, visualization and/or deep listening into my therapy with them. It's interesting though, even though at one level I don't have any real ethical dilemmas about the use of mindfulness in social work, at another level I do think that I need to engage in more exploration of the ethical dilemmas that could arise. 
These stories illustrate how these two practitioners have drawn on their own personal experience to inform their professional practice. The importance of experience as a source of knowledge is not an untold story within either the 'knowledge base' of social work (Drury Hudson, 1997; Trevithick, 2008) nor within that connected with the use of mindfulness in social work (Hick, 2008). Both Mari and Morgan came to see mindfulness as a personal/natural way of being that is useful to the well-being of themselves and their clients and consider it a personal or cultural practice that can be integrated into one's professional life or cultural practices. They saw mindfulness both as a practice and a social construct. This is reflected in the connections they made between how they were introduced to mindfulness and how they justified its use in their practice. Mari's own experience of understanding trauma and developing awareness through her body (Mensinga, 2011) informed her use of mindfulness in trauma/awareness work in her practice. Morgan's experience of it as a cultural practice was adapted and incorporated into the cultural context of social work. In both stories, the use of mindfulness in the professional context is monitored according to client characteristics and the participants' practice wisdom within the context of the 'professional story' (Healy, 2005).

\section{Mindfulness as a negotiated practice}

Lucy's story

I learnt about mindfulness through my own exploration of contemplative practices and the positive and negative challenges I have faced in life. My earliest experience would have been as a child, at Sunday School where I learnt about prayer and 'nonprayer'. Later I explored yoga, meditation, journaling, and different forms of spirituality and even immersed myself in a vegan lifestyle. I also remember learning 'if this happens, then ... breathe, listen, feel'. Through these experiences I came to understand mindfulness as 'being there in the moment' - letting myself listen without cross examining my intuitive/gut feelings; acknowledging and accepting rather than trying to diagnose or jump forward before the moment has been fully experienced or lived. In doing so, I consciously enjoy the moment and am aware of the feelings and experience - being still and calm in the busyness or chaos of life. It is part of who I am. It helps me to survive.

I take this understanding into the workplace and have engaged in a number of different activities with clients. For instance I have included drawing to various types of music; creative journaling with clients in a sexual assault service; a mindfulness exercise using Easter eggs with students; teaching clients to count backwards from 21 (in 3s); going to a happy place with deep breathing; and giving my full attention and focus so the other person knows that they are heard. I also think my practice has helped me in my ability to empathise and have respect person to person rather than client to worker/'expert' - cultivating equality rather than reinforcing a power imbalance. In fact, I think it is through listening (more), talking (less), listening (more than before), talking (less than before) and giving space for the words, I have learnt never to underestimate the capacity of others to find their solution. 
However, although I think of mindfulness as a 'halo' around my professional practice I do ask myself 'do I really know what I'm doing?' While I always consider things like the client's age, cognitive ability, and their willingness to participate in these activities- particularly as I currently work with involuntary clients who are mandated and/or court ordered - there are a number of questions that I also find myself asking. What is the stance of the professional accrediting body? Does this fit with the framework of the service? If it doesn't, is this able to change and if not am I then practising in an unethical manner? I think it is also made more difficult when my framework is not fully understood or valued by colleagues or supervisors in the sector. But there are also other difficulties- time and trying to slow things down in the current service/system is so hard. I am so aware of the competing requirements of completing 'tasks' and wanting to engage in an experience with my clients.

Lucy's story, like Mari's and Morgan's, still lies with the personal. However, while Lucy described meditation as a 'halo' around her practice, unlike the others she struggles with the implementation of it in her professional knowledge landscape. Mindfulness in her context is a negotiated practice that is more of a 'secret story' (Clandinin \& Connelly, 1996) about her work - not fully known, understood or valued by her colleagues and supervisors. Her story raises the importance of the 'professional story' and her struggle to reconcile professional knowledge, context and identity.

\section{The ethical practice of mindfulness}

David's story

Mindfulness allows me to be present in the moment, taking each moment as it comes. I describe it as a feeling of being merged with 'Brahman' (the source of power and eternity), which brings me peace within. However being able to achieve this state is difficult. Still, I believe it has great potential for us in our contemporary lives because people by nature would like to experience calm and peace of mind in life. Mindfulness, as a process, provides this opportunity for people, especially for those who find it difficult to pay attention in the present moment.

In my own practice I use techniques that are accepted by the social work profession based on research evidence from psychology, for example, the 3 minute breathing exercise and cognitive restructuring. These exercises enable the client to experience feelings and emotions and stay with them. While useful, I do have a number of dilemmas around social workers providing services to clients without having an adequate knowledge base and/or theoretical understanding behind mindfulness interventions. Although it has its roots in Buddhism, mindfulness has been developed and incorporated into the medical field. As a consequence, I believe that many practitioners present mindfulness as a 'capsule of techniques' that doesn't capture its rich traditions and practice wisdom. After all, within the eight fold path to wisdom 'paying attention' is only one of those paths. For example, I don't see any consideration given to the question 'why is there suffering 
on this earth?' - a question that is central to the noble truths of Buddhism. But then this raises issues at another level. I think the social work discourse needs to rethink the bio-psycho-social-cultural model and consider whether mindfulness as an element of spirituality needs to be included. This then raises questions about the 'value of the medical model versus traditional wisdom' and 'evidence based knowledge versus religious/spiritual knowledge'. Still, I do wonder why we want to create 'evidence' when mindfulness is already known to be effective in people's lives.

David's story is one where mindfulness as a spiritual activity has been given legitimacy by its incorporation into the medical field. To justify its use, it has been melded with the dominant discourse, but David questions what is lost in its adaptation to professional and organisational discourses. He sees a need to rethink these discourses from the perspective of traditional wisdoms and religious and spiritual knowledge. His concern is with the ethical practice of mindfulness. This story is similar in some respects to Morgan and Lucy's stories of working with mindfulness within the context of the professional and organisational discourses, though it differs in that David identified aspects of the 'sacred story' of social work that need to be rethought in light of the roots of mindfulness.

\section{How do social workers come to understand and incorporate mindfulness into practice?}

In light of the stories presented, just as Healy (2005) and Clandinin and Connelly (1996) concluded in their work, it is clear that how these social workers come to know about mindfulness and integrate it into their practice cannot be understood in a few sentences. Rather, we suggest that the importance of the eastern origins of mindfulness in their practice is a complex relationship between the storyteller's story of themselves as a practitioner of mindfulness, their 'professional story', stories of themselves as social workers and the story of social work in their professional knowledge landscape. Similarly, in keeping with this assertion, the four questions we posed at the beginning need to be answered conditionally, with an 'it depends'.

In our first question we asked 'How do social workers come to know about mindfulness?' The stories, from the participants' in our conversation 'Mindfulness in Social Work', reveal a knowledge and understanding of mindfulness largely grows out of personal experience, which includes an exposure to other cultures; physical challenges and/or their own interest in developing spiritual practices within and outside of traditional religious contexts. 'How they came to know' also includes learning through the body and engaging in contemplative experiences that lie outside the materialist/positivist, humanist and modernist principles of objectivity and rationality espoused by the profession. However, the stories also reveal that this knowledge is adapted, rather than preserved, into the 'professional story' both within the context of the professional and organisational discourses that arise on particular professional knowledge landscapes. Furthermore, while stories like Morgan and David's reveal a confidence about integrating mindfulness into practice, Lucy's awareness of prevailing professional and organisational discourses mean she uses it opportunistically. We wonder whether a 
shift in values would encourage Lucy and others like her to no longer cosset a 'secret story' about mindfulness, but instead contribute their stories to a growing body of knowledge that can then be explored in more depth by others.

In relation to our second question 'What do social workers know about the effective use of mindfulness in social work?' our answer of 'it depends' is even more apparent. In the stories that Mari, Morgan, Lucy and David tell about what might constitute the form and effective use of mindfulness in social work, there appears to be a direct link between the stories they tell about what it means for them to be a practitioner of mindfulness and those that reveal their understanding of the professional knowledge landscape. Similar to Healy's (2005) description of the 'professional story', their social work story of mindfulness changes within different organisations and fields. For example, the effective use of mindfulness in Lucy's story is defined more by the culture, values and norms of her organisation and those committed to valuing such work rather than by any tested knowledge base or personal practical experience. Once again, we believe that it is only by changing the dominant and service discourses and the values they foster that a practice once seen as strange or ineffectual may become valued on the professional knowledge landscape.

We suggest that the stories also indicate that a conditional 'it depends' applies to the remaining questions we have posed - i.e., what knowledge do social workers consider essential for using mindfulness and who do social workers trust to produce knowledge about mindfulness in social work? All four stories suggest that client characteristics' and their defined needs, the agency context and how the practitioner perceives their own social work identity determines what knowledge is essential when using mindfulness in practice. Mari, Morgan, Lucy and David also indicate a need to adapt the knowledge they had acquired from their own personal experiences when using mindfulness in their professional practice. David, for example, turned to medical sources about mindfulness as a trusted source of knowledge production to help integrate his knowledge into practice. On the other hand, David also questions this process and suggests that a deeper understanding of the epistemological underpinnings of mindfulness is just as important as modifying techniques to fit a western context. However, although there is a vast knowledge base about mindfulness in Buddhist and other religious literature and more recently an emerging knowledge base in social work that could be drawn on when introducing mindfulness in practice, the participants' stories reveal that choosing knowledge that enables them to navigate the different components of the 'professional story' is more important.

\section{Summary and possibilities}

Although the four stories presented in this article are examples of the written narratives collected in the workshops, these stories reflect the content and processes described in the remaining narratives. All the practitioners who participated in the workshops, even those who had yet to include mindfulness into their practice, noted an emerging knowledge system about mindfulness in social work and described a map of how social workers move through and responsibly use mindfulness within the 'professional story' (Healy, 2005). Knowledge creation within social work has traditionally relied 'on the assumption that systematically produced, "scientific", generalised and generalisable 
(propositional) knowledge provides the most solid foundations for practice' (Taylor, 2006: 4 in Trevithick, 2008: 1215). Contrary to this approach, these stories suggest that knowledge and use of mindfulness in social work is a contextual and relational process with social worker knowledge taking shape as their narrative of practice in the professional knowledge landscape unfolds. For some social workers, their own positioning within space, place and time in the professional context may create epistemological dilemmas around mindfulness that we understand narratively as 'secret' and 'sacred' stories (Clandinin \& Connelly, 1996). These arise as they negotiate the 'professional story' of social work, within their professional knowledge landscape and what is considered to be appropriate knowledge for practice and practice decisions.

We believe that these stories show that the deeply contextual nature of the 'professional story' of social work indicates that the development of social work knowledge of mindfulness and embodied awareness requires new questions that take account of the complex environment in which social workers negotiate and undertake their practice. Moreover, it also highlights the need for new ways of understanding and relating to social workers' experience of reconciling mindfulness into their professional knowledge, context and identity within their 'professional story', and further exploration of the unique challenges and influences on the use of mindfulness in social work.

\section{Acknowledgements}

This manuscript has been supported by the CQUniversity HEALTH CRN www.cqu. edu.au/crn and the Australian Government's Collaborative Research Networks Program.

\section{Disclosure statement}

No potential conflict of interest was reported by the authors.

\section{References}

Bamberg, M (2006) 'Stories: big or small why do we care?', Narrative Inquiry, vol. 16, no. 1 , pp. $139-147$.

Bell, K (2012) 'Towards a post-conventional philosophical base for social work', British Journal of Social Work, vol. 42, pp. 408-423.

Berceli, D. \& Napoli, M (2006) 'A proposal for mindfulness-based trauma prevention program for social work professionals', Complementary Health Practice Review, vol. 11, pp. $153-165$.

Birnbaum, L. \& Birnbaum, A (2008) 'Mindful social work: from theory to practice', Journal of Religion and Spirituality In Social Work: Social Thought, vol. 27, no. 1-2, pp. $87-104$. 
Bishop, SR, Lau, M, Shapiro, SS, Carlson, L, Anderson, ND, Carmody, J, Segal, ZV, Abbey, S, Speca, M, Velting, D. \& Devins, G (2004) 'Mindfulness: a proposed operational definition', Clinical Psychology: Science and Practice, vol. 11, no. 3, pp. $230-241$.

Bodhi, B (2011) 'What does mindfulness really mean? a canonical perspective', Contemporary Buddhism, vol. 12, no. 1, pp. 19-39.

Clandinin, DJ \& Connelly, FM (1995) Teachers' professional knowledge landscapes, Teachers' College Press, New York.

Clandinin, DJ \& Connelly, FM (1996) 'Teachers' professional knowledge landscapes: Teacher stories-stories of teachers-school stories-stories of schools', Educational Researcher, vol. 25, pp. 24-30.

Clandinin, DJ \& Connelly, FM (2000) Narrative Inquiry Experience and Story in Qualitative Research, John Wiley \& Sons Inc, San Francisco.

Coholic, D (2005) 'The helpfulness of spiritually influenced group work in developing selfawareness and self-esteem: a preliminary investigation', The Scientific World Journal, vol. 5, pp. 789-802.

Drury Hudson, J (1997) 'A model of professional knowledge for social work practice', Australian Social Work, vol. 50, no. 3, pp. 35-44.

Fenstermacher, GD (1994) 'The knower and the known: The nature of knowledge in research on teaching', Review of Research in Education, vol. 20, pp. 3-56.

Fook, J. (2002) Social work: Critical theory and practice, Sage Publications, London.

Fook, J, Ryan, M. \& Hawkins, L (2000) Professional Expertise: Practice, theory and Education for Working in Uncertainty, Whiting and Birch, London.

Gause, R. \& Coholic, D (2010) 'Mindfulness based practices as a holistic philosophy and method', Currents: New Scholarship in the Human Services, vol. 9, no. 2, http:// currents.synergiesprairies.ca/currents/index.php/currents/article/view / 42 (accessed 14 April 2013).

Grossman, P. \& Van Dam, NT (2011) 'Mindfulness, by any other name... : Trials and tribulations of Sati in Western Psychology and science', Contemporary Buddhism, vol. 12, no. 1, pp. 219-239.

Hanh, T. N. (1976) The Miracle of Mindfulness, Beacon Press, Boston, MA.

Healy, K (2005) Social Work Theories in Context: Creating Frameworks for Practice, Palgrave MacMillan, Basingstoke.

Hick, SF (2008) 'My personal journey to mindfulness: implications for social work', Reflections: Narratives of Professional Helping, vol. 14, no. 2, pp. 16-23.

Hick, SF (2009) Mindfulness and Social Work, Lyceum Books, Inc, Chicago, IL.

Hick, SF \& Furlotte, C (2009) 'Mindfulness and social justice approaches: Bridging the mind and society in social work practice', Canadian Social Work, vol. 26, no. 1, pp. 5-25.

Lee, M, Ng, S, Leung, P \& Chan, C (2009) Integrative Body-Mind-Spirit Social Work. An Empirically Based Approach to Assessment and Treatment, Oxford University Press, New York.

Lynn, R (2010) 'Mindfulness in Social Work Education', Social Work Education, vol. 29, no. 3, pp. 289-304.

Lynn, R, Mensinga, J, Tinning, B \& Lundman, K (2015) 'Is mindfulness value free? Tip toeing through the mindfield of mindfulness', in Holistic Social Work Education in the 21st Century, eds L Pyles \& G Adam, Oxford University Press, New York, NY. 
Mensinga, J (2010) Quilting Professional Stories. A Gendered Experience of Choosing Social Work as a Career, VDM Verlag Dr. Muller Aktiengesellschaft \& Co. KG, Saarbrucken.

Mensinga, J (2011) 'The feeling of being a social worker: including yoga as an embodied practice in social work education', Social Work Education, vol. 30, no. 6, pp. 650-662.

Milton, I (2011) 'What does mindfulness really mean? Clarifying key terms and definitions: Part 1', Psychotherapy in Australia, vol. 17, no. 4, pp. 24-27.

Minor, HG. \& Carlson, LE (2006) 'Evaluation of mindfulness-based stress reduction (MBSR) program for caregivers of children with chronic conditions', Social Work in Health Care, vol. 43, no. 1, pp. 91-109.

Ollerenshaw, JA. \& Creswell, JW (2002) 'Narrative research: A comparison of two restorying data analysis approaches', Qualitative Inquiry, vol. 8, pp. 329.

Payne, M (1996) What is Professional Social Work? Venture Press, London.

Riessmann, CK (2007) Narrative Methods for the Human Services, Sage Publications, London.

Segal ZV, Hick SF. \& Bien T (2010) Mindfulness and the Therapeutic Relationship, Guildford Publications, New York.

Taylor, C (2006) 'Narrating significant experience: Reflective accounts and the production of (self) knowledge', British Journal of Social Work, vol. 36, pp. 189-206.

Turner, K (2009) 'Mindfulness The present moment in clinical social work', Clinical Social Work Journal, vol. 37, no. 2, pp. 95-103.

Trevithick, P (2008) 'Revisiting the knowledge base of social work: A framework for practice', British Journal of Social Work, vol. 38, pp. 1212-1237.

Wallace, BA (2006) The Attention Revolution, Wisdom, Boston.

Wallace, BA (2011) Minding Closely: The Four Applications of Mindfulness, Snow Lion, New York.

Wallace, BA (2012) Meditations for a Buddhist Sceptic: A Manifesto for the Mind Sciences and Contemplative Practice, Columbia University Press, New York, NY.

Robyn Lynn James Cook University, P.O. Box 6811, Cairns, QId, 4870, Australia. [email: robynlynn@westnet.com.au]

Jo Mensinga James Cook University, P.O. Box 6811, Cairns, QId, 4870, Australia. [email: jo.mensinga@jcu.edu.au] 